are riddled with shrapnel and bullets and torn by fragments of shell, while here and there unexploded shells may still be seen embedded in the stems. Aveluy Wood, however, affords another example of the effort being made by Nature to beautify the general scene of desolation. Here some of the trees are still alive, though badly broken, but the ground beneath is covered with a dense growth of the rose-bay willow herb (Epilobium angustifolium) extending over several acres. Seen from across the valley, this great sheet of rosy-pink was a most striking object, and the shattered and broken trees rising out of it looked less forlorn than elsewhere.

The innumerable shell-hole ponds present many interesting features to the biologist. In July they were half-full of water, and abounded in water beetles and other familiar pond creatures, with dragonflies flitting around. In nearly every shell-hole examined, just above the water-level, was a band of the annual rush (Juncus bufonius, var. gracilis), and this plant appeared to be confined to those zones where the ground was relatively moist, and to occur nowhere else. With the Juncus, and often growing out of the water, were stout plants of Polygonum persicaria, and water grasses, not in flower, were often seen spreading their leaves over the surface of the pools.

In the battlefield area not only were the common cornfield weeds to be seen, but here and there patches of oats and barley, and occasionally plants of wheat, sometimes apparently definitely sown, perhaps by the Germans, though more often the plants must have grown from self-sown seeds of crops that were on the land before the war. Here and there, too, could be seen opium poppies representing former cultivation and remnants of battered currant and other bushes which alone remained to show where once had been a cottage garden. Both weeds and corn afford good evidence that the soil has not been rendered sterile by the heavy shelling, but how and when the land can be brought into a fit state for cultivation are questions not easily answered.

On the banks and sides of the roads traces of the old permanent flora still remain, and perennial plants, such as Scabiosa arvensis, Eryngium campestre, Galium verum, chiccry, Centaurea scabiosa, Cnicus acaulis, and other characteristic chalk plants were occasionally seen.

The clothing of this large tract of country with such a mass of vegetation composed almost entirely of common annual cornfield weeds is remarkable when one remembers that it has been the seat of encampments, and for the most part out of cultivation since the autumn of ral4. It is well-nigh impossible that such masses of seed can have been carried by wind or birds to cover these thousands of acres, and the plants must therefore have grown from seed lying dormant in the ground. No doubt in the ordinary operations of ploughing and tilling of the ground in years before the war much seed was buried which has been brought to the surface by the shelling of the ground and subsequent weathering. In this connection the presence of charlock on the more recently dug graves, where the chalk now forms the actual surface, is of interest, since it adds further proof of the longevity of this seed when well buried in the soil.

\section{List of Plants.}

Delphinium Ajacis, Reichb., larkspur; Papaver Rhoeas, L., poppy; Fumaria officinalis, L., fumitory; Raphanus Raphanistrum, L., white charlock; Brassica sinapis, Vis., yellow charlock; Matricaria chamomilla, L., chamomile; Centaurea cyanus, L., cornflower; Cnicus arvensis, Hoffm., thistle; Sonchus arvensis, L., corn sowthistle; Sonchus oleraceus, L., NO. 2520 , VOL. IOO] sowthistle; Specularia speculum, A. DC, looking-glass flower; Anagallis arvensis, L., scarlet pimpernel; Myosotis arvensis, Hoffm., forget-me-not; Convolvulus arvensis, L., small bindweed; Solanum nigrum, L. nightshade; Plantago major, L., etc., plantain; Veronica hederatfolia, L., etc., speedwell; Galeopsis ladanum, L., hemp-nettle; Chenopodium album, L., goosefoot; Atriplex patula, L., orache; Polygonum aviculare, L., knotgrass; Polygonum persicaria, L., persicaria; Rumex obtusifolius, L., dock; Euphorbia helioscopia, L., sun spurge; Mercurialis annua, L., dog's mercury; Juncus bufonius, L., var. gracilis, St. Amand rush. A few grasses and occasional plants or patches of oats, barley, and wheat.

\section{COAL CONSERVATION AND ELECTRIC POWER SUPPLY.}

WE referred in our issue of January 3 to the. interim report on electric power supply in Great Britain prepared by the Coal Conservation Sub-Committee of the Reconstruction Committee. Dr. C. Addison, Minister of Reconstruction, states in an introductory note that the important issues affecting municipalities and public bodies raised in the report will be explored in all respects by the Government before any action is proposed to Parliament upon the subject.

The report deals, first, with the extent to which conservation of coal could effect economy in the production of motive power and other forms of energy used for industrial purposes in this country; secondly, with the expansion of industry which should result, in the way of new manufactures, from the proper use of the coal so saved; and thirdly, with the steps necessary to attain these objects.

It contains many valuable tables and other details, and the following summary of the chief points dealt with and the conclusions arrived at:-

(r) The coal consumption involved in the production of motive power in the United Kingdom amounts at the present time to $80,000,000$ tons per annum, equivalent in value to, say, 40,$000 ; 000$. at pit-head.

(2) In the industrial reorganisation which must take place on the termination of the war the further development of power is of great importance. The present use of motive power per employee is only about half that in the United States of America. Large quantities of electrical power will be required for the development and carrying on of new processes not at present undertaken in this country. Processes involving some millions of horse-power at present worked in America, Norway and Sweden, Germany, etc., can be profitably carried on, and, having in view the desirability of making all essential products in the Empire, should be carried on in this country.

(3) It is only by largely increasing the amount of power used in industry (by two or more times) that the average output per head (and as a consequence the wages of the individual) can be increased. The prewar earning power, or wages, of each individual was far too low.

(4) Power may be most efficiently applied to industry by the medium of electricity.

(5) The economical generation of the electrical energy so required is thus of great importance, and the first question to be answered is whether the best economy can be obtained by each works or municipal area providing for its own individual needs, or by a comprehensive scheme.

(6) Technically and economically the electrical energy can be best provided by a comprehensive system, as may be amply proved from experience gained in those 
parts of the world where such systems are in existence, notably in Chicago (Illinois), on the north-east coast of England, on the Rand, and in certain industrial districts of Germany. Power production in large superplants, with generating machines of 50,000 h.p. or more, will not only be far more economical than in a large number of smaller plants, but will also ultimately involve great economies of capital by securing a better load and a more effective use of the plant. Such super-plants, if suitably situated on large sites, would make it possible--so far as it was economical to do so - to extract the by-products in the shape of oils, motor spirit, etc., from the coal before using it as fuel, thus avoiding to a large extent the necessity of importing them.

(7) The super-plants would feed into the main trunk distribution system, which must be laid down throughout the country. For this purpose the country should be divided into some sixteen districts, throughout each of which there should be a standard periodicity and main trunk voltage.

(8) This main trunk distribution system would collect any waste power available wherever situated and deliver it where it could be profitably used. It would also, by saving the cost of transport, make it commercially possible to bring to the surface much coal at present wasted and left in the pit which, under the new conditions, would be turned into electrical energy at or near the pit-head.

(9) If power supply in the United Kingdom were dealt with on comprehensive lines and advantage taken of the most modern engineering development, the saving in coal throughout the country would, in the near future, amount to $55,000,000$ tons per annum on the present output of manufactured products.

(ro) If the coal so saved were used for the production of further power it would be possible to generate continuously not fewer than $\mathrm{I}_{5}, 000,000$ horse-power, which would more than compensate for the absence of large water powers in this country and admit of the manufacture here of many products which are at present made only in America and on the Continent.

(II) The development of such a power system may be likened to the development of the railways of a country, and it is just as impossible to secure economical power generation and supply by each municipal area working independently, which is the position to-day, as it would be to have an efficient railway system if each municipal area owned its own lines, and long-distance transport were provided for by running-power agreements. History shows that in the early stages of railway development in this country exactly the same process of amalgamation had to be gone through.

(I2) The present system of electrical power distribution throughout the country, which is undertaken by more than 600 authorities in as many separate districts, is technically wrong and commercially uneconomical. The present average size of a generating station is only 5000 horse-power, or about one-fourth of what should now be the smallest generating machine in the power station. The "Power Act" legislation inaugurated some fifteen years ago has not had the desired result on account of the restrictions imposed upon the power companies.

(I3) A national system of electric power supply would greatly facilitate the electrification of railways with its attendant advantages. save large sums of money at present spent on the transport and distribution of coal, and bring within reach of the community as a whole the great benefits of an increase in the use of electricity for domestic purposes, advantages which, taken together, are perhaps of more value than the direct coalsaving.

NO. 2520, VOL. IOO]

\section{PHYSICAL SCIENCE AND THE ART OF EXPERIMENT. ${ }^{1}$}

THE exigencies of the war had seriously impeded the work of the Physical Society, as of all our scientific institutions. Many members were at the front; many others were busy on war work, and there was little time available for normal scientific pursuits Since his predecessor's address, the scientific community had been stirred to an extent which he thought was unnecessary by the passing of the Daylight Saving Act. Scientifically the thing was a sham, and as such was naturally distasteful to us; but the community at large was not scientific, and had a very vague notion of the meaning of time. In the stress of war people had realised the desirability of starting the day earlier to save, not daylight, but paraffin and gas, and the simple operation of putting all the clocks wrong, though hateful in principle, did not disturb the public at all.

In reference to the question of the metric system, this was important in relation to education. The reason why English schools were so backward in mathematics was that so much of the available time had to be devoted to memorising tables of weights and measures and similar medieval relics.

Another matter of public importance was the recognition of science as an element of general education. It is sometimes urged that our officials need not be scientific, because they can get all the scientific advice they want. But they may not know when they require it, or appreciate the force of it when they get it. $\mathrm{He}$ might instance in this connection the wasteful method of street darkening which still prevails after three years. The annual trouble with frozen water pipes was another example of the general ignorance of scientific principles. Burst pipes were unknown in really cold countries, where the elements of common sense were dilowed to prevail.

All his own contributions to physical science had been experimental, and some words on the art of experiment might not be out of place. In order to succeed as an experimentalist it was necessary to find by personal experience how as many materials as possible behave under as many conditions as possible, and this can only be done by one who will practise every art and use every tool and instrument that he can. While endeavouring at first to imitate the practices of the professional mechanic and acquire as much of his skill as possible, the experimentalist must not be bound by tradition and custom in his methods. It is the slavery to tradition and practice that makes the assistance of the professional so tiresome to the experimentalist. In this connection a saying of Fresnel had greatly impressed him-" If you cannot saw with a file and file with a saw you will be no use as an experimentalist," or words to that effect. He had made it his business to use every tool and to handle every material that he could. On one occasion he had had the somewhat rare opportunity of handling five or six large uncut diamonds, each as big as a walnut. Glass-blowers are familiar with the difference in the contact of freshly blown bulbs and of bulbs some time blown; but the contact of diamonds was unlike either. When brought lightly into contact they emit a curious squeaking note of possibly 2000 vibrations per second. This meant that the diamonds were bouncing with slowly diminishing excursions of $\mathrm{x} / 8 \mathrm{0}, 000$ of an inch approximately, a phenomenon only possible with a material of such perfect elasticity or hardness. It was possible that a test of this kind might be useful for discriminating between the hardness of the harder materials. The whole question of what hardness was, and if, indeed, it were really

1 Abstract of the presidential address delivered to the Physical Society January 25 by Prof. C. V. Boys, F.R.S. 